\title{
Partially ionized medical oxygen as a supplementary treatment for COVID-19
}

\author{
Slavomír Perečinský (D) · Viliam Donič · Ľubomír Legáth
}

Received: 29 April 2020 / Accepted: 4 July 2020 / Published online: 30 July 2020

(C) Springer-Verlag GmbH Austria, part of Springer Nature 2020

\section{Letter to the editors}

\section{Dear Editors,}

we read with interest the recent report by Rowen and Robins regarding the effective treatment for "novel coronavirus" SARS-CoV with ozone therapy [1]. The authors explained the effect of ozone therapy through oxidation of the membrane glycoproteins, where thiol groups in reduced form (R-S-H) are changed to disulphide (R-S-S-H). Then, viral enzymes can become inactive when reduced thiols are oxidized. Coronavirus structure has regions rich in cysteine, which are vulnerable to oxidation. The COVID-19 is real worldwide pandemic with significant morbidity and mortality, so there is an emergency to find many other treatment methods. We fully agree with the authors that in some conditions, in which there are limitations in conventional treatment, oxidation therapy could be useful; however, we would like to share our thoughts and contributions to this report.

Another type of oxidation therapy is administration of partially ionized oxygen. Although it is not a frequently used method, its success was proven. Therapy with ionized oxygen (Ionized Oxygen Therapy $-\mathrm{IO}_{2} \mathrm{Th} /$ Engler) is a physical, adjuvant, short-term medical administration of partially ionized oxygen. This method was developed in 1980 by Assoc. Prof.

\footnotetext{
S. Perečinský $(\bowtie) \cdot$ L'. Legáth

Department of Occupational Medicine and Clinical

Toxicology, Medical Faculty, Pavol Jozef Safarik

University and Louis Pasteur University Hospital,

Rastislavova 43, 04190 Kosice, Slovakia

slavomir.perecinsky@upjs.sk

V. Donič

Department of Medical Physiology, Medical Faculty, Pavol Jozef Safarik University, Tr. SNP 1, 04001 Kosice, Slovakia
}

Ivan Engler, MD, PhD. from Salzburg. Partially ionized oxygen $\left(\mathrm{O}_{2} \bullet, \mathrm{O}_{2}^{+} \bullet\right)$ can be produced by ionization of medical oxygen $\left(\mathrm{O}_{2}\right)$ in the high-voltage chamber of the Oxygen Ion 3000/Dr. Engler device. The device has been commercially available since 2000 and is produced by CS Tronic (St Pantaleon, Austria) as a medical device with EU certification. It is commonly used for the treatment of bronchial asthma [2]. The benefit of this method was also confirmed in other diagnoses [3, 4]

The effect of $\mathrm{O}_{2}^{-} \bullet$ is similar to $\mathrm{O}_{3}: \mathrm{O}_{2}^{-} \bullet$ is a very potent free oxygen radical, which induces direct inactivation of the virus through oxidation of the membrane glycoproteins. Compared to ozone it has one significant advantage. Ozone is highly irritating to the lungs and cannot be inhaled. Therefore, it is most commonly administered by direct intravenous application [5]. On the other hand, oxygen ions, both positive and negative, can be safely inhaled. Additionally, oxygen therapy is essential for severe cases of COVID19 [6]. A different view on management of COVID19 is to decrease the adverse effect of long-term oxygen therapy. Hyperoxia induces lung injury resulting from direct oxygen toxicity and the accumulation of inflammatory cells and mediators within the lungs [7]. In vitro study confirmed that long-term inhalation of partially positively ionized oxygen $\left(\mathrm{O}_{2}+\bullet\right)$ was associated with less oxidative stress, better ability to secure airway patency and milder lung inflammatory response than molecular oxygen. Another promising result was a lower degree of lung desiccation in animals with positively and negatively ionized oxygen in comparison to molecular oxygen. There is no need for humidification of inhaled partially ionized oxygen [8]. The similar benefit of $\mathrm{O}_{2}+\bullet$ was found even in myocardial and brain cells of guinea pigs [9, 10].

The main limitation of this method is the need for a special medical device which means it is not ap- 
plicable outside hospital conditions. Secondly, at the moment the effective time of inhalation $\mathrm{O}_{2} \bullet$ for virus inactivation has not yet been estimated.

However, we believe that partially ionizing oxygen therapy will be a useful supplementary treatment of COVID-19, especially in lung damage protection.

Conflict of interest S. Perečinský, V. Donič and L'. Legáth declare that they have no competing interests.

\section{References}

1. Rowen RJ, Robins H. A plausible "penny" costing effective treatment for corona virus-ozone therapy. J Infect Dis Epidemiol. 2020;6:113.

2. Gaisberger M, Sanovic R, Dobias H, et al. Effects of ionized waterfall aerosol on pediatric allergic asthma. J Asthma. 2012;49:830-8.

3. Perecinsky S, Murinova L, Engler I, et al. Effect of partially ionized medical oxygen, especially $\mathrm{O}_{2}-\bullet$ in vibration white finger patients. Int J Environ Res Public Health. 2014;11:5698-707.

4. TorokP,DonicV, Engler I, etal. Pulmonary arterial hypertension influenced by inhalation of partially negative ionized oxygen (O2•). Int J Biol Pharm Res. 2015;6:345-50.

5 . Rowen RJ. Ozone and oxidation therapies as a solution to the emerging crisis in infectious disease management: a review of current knowledge and experience. Med Gas Res. 2019;9:232-7.

6. Clinical management of severe acute respiratory infection when novel coronavirus (nCoV) infection is suspected. https://www.who.int/publications-detail/ clinical-management-of-severe-acute-respiratoryinfection-when-novel-coronavirus-(ncov)-infection-issuspected. Accessed 10 Mar 2020.

7. Zaher TE, Miller EJ, Morrow DMP, Javdan M, Mantell LL. Hyperoxia-induced signal transduction pathways in pulmonary epithelial cells. Free Radic Biol Med. 2007;42:897-908.

8. Calkovska A, Engler I, Mokra D, et al. Differences in oxidative status, lung function, and pulmonary surfactant during long-term inhalation of medical oxygen and partially ionized oxygen in guinea pigs. J Physiol Pharmacol. 2008;59:173-81.

9. Kaplan P, Tatarkova Z, Engler I, et al. Effects of long-term oxygenation treatments on a-ketoglutarate dehydrogenase activity and oxidative modifications in mitochondria of guinea pig heart. Eur J Med Res. 2009;14:116-20.

10. Tatarkova Z, Engler I, Calkovska A, et al. Effect of long-term normobaric hyperoxia on oxidative stress in mitochondria of the guinea pigbrain. Neurochem Res. 2011;36:1475-81.

Publisher's Note Springer Nature remains neutral with regard to jurisdictional claims in published maps and institutional affiliations. 